\title{
Hyperoxia accelerates Fas-mediated signaling and apoptosis in the lungs of Legionella pneumophila pneumonia
}

\author{
Tsuneharu Maeda ${ }^{1,2}$, Soichiro Kimura ${ }^{1 *}$, Tetsuya Matsumoto ${ }^{3}$, Yoshinari Tanabe $^{2}$, Fumitake Gejyo ${ }^{2}$ and \\ Keizo Yamaguchi ${ }^{1}$
}

\begin{abstract}
Background: Oxygen supplementation is commonly given to the patients with severe pneumonia including Legionella disease. Recent data suggested that apoptosis may play an important role, not only in the pathogenesis of Legionella pneumonia, but also in oxygen-induced tissue damage. In the present study, the lethal sensitivity to Legionella pneumonia were compared in the setting of hyperoxia between wild-type and Fas-deficient mice.

Findings: C57BL/6 mice and B6.MRL-Fas ${ }^{1 p r}$ mice characterized with Fas-deficiency were used in this study. After intratracheal administration of L. pneumophila, mice were kept in hyperoxic conditions (85-90\% $\mathrm{O}_{2}$ conc.) in an airtight chamber for 3 days. Bone-marrow derived macrophages infected with L. pneumophila were also kept in hyperoxic conditions. Caspase activity and cytokine production were determined by using commercially available kits. Smaller increases of several apoptosis markers, such as caspase-3 and -8, were demonstrated in Fas-deficient mice, even though the bacterial burdens in Fas-deficient and wild type mice were similar. Bone-marrow derived macrophages from Fas-deficient mice were shown to be more resistant to Legionella-induced cytotoxicity than those from wild-type mice under hyperoxia.
\end{abstract}

Conclusions: These results demonstrated that Fas-mediated signaling and apoptosis may be a crucial factor in the pathogenesis of Legionella pneumonia in the setting of hyperoxia.

\section{Introduction}

Legionella pneumophila is a Gram-negative intracellular pathogen, and often causes a severe and life-threatening pneumonia [1,2]. Legionella pneumonia is frequently complicated with acute lung injury and acute respiratory distress syndrome, which exaggerates the severity of this disease $[3,4]$. Despite aggressive supportive care, including antibiotic therapy and oxygen supplementation, high mortality rates have been reported, especially in immunocompromised patients $[3,5,6]$.

Multiplication of L. pneumophila in lung tissue is shown in several types of host cells, including macrophages, monocytes, and alveolar epithelial cells [7-9]. Previous reports showed that L. pneumophila can induce apoptosis in macrophages and alveolar epithelial

\footnotetext{
* Correspondence: kimsou@med.toho-u.ac.jp

'Department of Microbiology and Infectious Diseases, Toho University

Faculty of Medicine, Tokyo 143-8540, Japan

Full list of author information is available at the end of the article
}

cells [10-12]. Apoptosis is a highly regulated process of cell death that is required for development and homeostasis of multicellular organisms in physiological condition $[13,14]$. The two apoptosis pathways are the extrinsic and intrinsic pathways [15]. The extrinsic pathway is initiated by stimulation of the transmembrane death receptors by specific ligands such as Fas, and then procaspase 8 is proteolytically activated. Procaspase 8 proteolytically activates effectors proteins such as caspase 3 and caspase 7. The intrinsic pathway is usually activated by apoptotic signals such as cell stress. The stimuli cause changes to the inner mitochondrial permeability and then cytochrome $\mathrm{c}$ is released into the cytosol. The release of cytochrome c stimulates apoptosome formation, and can lead to the activation of caspase-9, and then of caspase-3. A wide variety of pathogens were reported to modulate the host celldeath pathway by direct interaction with key components of the apoptosis machinery of the host $[16,17]$.
C Biomed Central

() 2010 Kimura et al; licensee BioMed Central Ltd. This is an Open Access article distributed under the terms of the Creative Commons Attribution License (http://creativecommons.org/licenses/by/2.0), which permits unrestricted use, distribution, and reproduction in any medium, provided the original work is properly cited. 
Unfortunately, how apoptosis is involved in the pathogenesis of Legionella disease is incompletely understood.

Supplementation with oxygen is a critical part of supportive care for severe pneumonia, including Legionella infection, as an adjunct to intensive antibiotic chemotherapy. Unfortunately, prolonged administration of oxygen itself may be associated with exaggeration of lung damage in these patients [18]. Recent progress in this field suggests an important role for apoptosis in hyperoxia-mediated lung injury in a variety of cells, such as epithelial cells and microvascular endothelial cells [19-21]. In a previous study, we found that hyperoxia caused the development of acute lung injury and lethality in mice with Legionella pneumonia [22]. However, only limited information is available for about the significance of hyperoxia in pathogenesis of Legionella pneumonia, especially from the standpoint of apoptosis in the infected lungs.

In the present study, we examined Legionella pneumonia associated with Fas-mediated apoptosis in the setting of hyperoxia. To understand the mechanism of lethal sensitivity, several apoptosis markers including caspase$3,-8$, and cytokine productions were explored.

\section{Materials and methods}

\section{Animals}

Specific pathogen-free 6-to 10-wk-old C57BL/6 mice (Charles River Japan, Tokyo, Japan) and B6.MRL-Fas ${ }^{l p r}$ mice characterized with Fas-deficiency (The Jackson Laboratory, Bar Harbor, ME) were used. Fas-deficient mice were bred in our animal facility. All mice were housed in specific pathogen-free conditions within the animal care facility at Laboratory Animal Research Center of Toho University of Medicine until the day of sacrifice (approved number \#169).

\section{Culture of Legionella organism and inoculation of bacteria in vivo}

We used a clinical isolate of L. pneumophila Suzuki strain (serogroup 1) for all experiments. $N$-(2-acetamido)-2-aminoethanesulfonic acid (Sigma-Aldrich, St. Louis, MO)-buffered yeast extract (BYE) broth supplemented with L-cysteine $(0.4 \mu \mathrm{g} / \mathrm{ml})$ and ferric nitrate $(0.135 \mu \mathrm{g} / \mathrm{ml})$ was used as liquid medium (BYE-broth). To prepare solid medium, activated charcoal $(2 \mu \mathrm{g} / \mathrm{ml})$ and agar $(15 \mu \mathrm{g} / \mathrm{ml})$ were added to liquid medium (BCYE agar). L. pneumophila was incubated on BCYEagar for 4 days at $37^{\circ} \mathrm{C}$. A single colony was transferred to $3 \mathrm{ml}$ of BYE-broth, and was then incubated overnight at $37^{\circ} \mathrm{C}$ with constant shaking. The bacterial suspension was again transferred to fresh BYE-broth, and incubated overnight under the same conditions. The bacterial suspension was diluted to the desired concentrations in saline according to a standard of absorbencies based on known CFU. Animals were anesthetized intraperitoneally with 2.2 and $11.1 \mathrm{mg} / \mathrm{kg}$ xylazine and ketamine, respectively. The trachea was exposed and $30 \mu \mathrm{l}$ of inoculum was administrated via a sterile 26 gauge needle. The skin incision was closed with surgical staples.

\section{Oxygen exposure in vivo}

After intratracheal (i.t.) administration of bacteria, one group of mice was kept in hyperoxic conditions in an airtight chamber for 3 days, whereas another group was placed in room air conditions according to our previous studies [22,23]. For hyperoxic exposure, the oxygen concentration in the chamber was kept between 85 and $90 \%$ by a constant flow gas, which was monitored with an in-line oxygen analyzer $\left(\mathrm{O}_{2}\right.$ CONTROLLER model MC-70, IIJIMA Electronics Corp. Japan) [22]. Carbon dioxide levels in the chamber were maintained at $0.03-$ $0.04 \%$ during the course of experiments. Both groups of mice were fed food and water ad lib and kept on a 12-h dark night cycle at room temperature.

\section{Lung harvesting for analysis}

At designated time points, mice were sacrificed using $\mathrm{CO}_{2}$ asphyxia. Before the lung removal, the pulmonary vasculature was perfused with $1 \mathrm{ml}$ of saline, via the right ventricle. Whole lungs were then harvested for assessment of bacterial number, cytokine protein expression, and apoptosis [22]. After the removal of whole lungs, they were homogenized in $1.0 \mathrm{ml}$ of saline using a tissue homogenizer (Omni TH HOMOGENIZER, YAMATO scientific products Co,. Ltd., Tokyo) under a vented hood. Portions of homogenates $(10 \mu \mathrm{l})$ were inoculated on agar after serial 1/10 dilutions with saline. The remaining homogenates were centrifuged at 2000 $\mathrm{rpm}$ for $10 \mathrm{~min}$ in $4^{\circ} \mathrm{C}$. Supernatants were collected, and passed through a $0.45-\mu \mathrm{m}$ filter (KANTO CHEMICAL CO,. INC, Tokyo). These samples were stored at $-20^{\circ} \mathrm{C}$ for further analysis.

\section{Oxygen exposure in vitro}

The BM-derived macrophages infected with Legionella in 96-well plates were kept in hyperoxic conditions in a multi gas incubator (ASTEC Co,. Ltd, TOKYO) and incubated at $37^{\circ} \mathrm{C}$ in $85-90 \%$ of oxygen and $5 \%$ of $\mathrm{CO}_{2}$. In normoxia experiments, the plate was kept in $5 \% \mathrm{CO}_{2}$ incubator during the course of experiments.

\section{Preparation of bone-marrow derived macrophage}

Murine bone-marrow (BM) derived macrophages were prepared from control C57BL/6 and Fas-deficient mice by the following method [24]. BM cells were extracted from femurs, and suspended in RPMI with L-glutamine added $10 \%$ fetal bovine serum $(10 \mathrm{ml}$ per mouse). The BM cells in $2 \mathrm{ml}$ were plated in the cell 
incubate dishes (BIOCOAT) and then added $8 \mathrm{ml}$ (per dish) of RPMI with L-glutamine containing L929 cell conditioned medium (20\%), fetal bovine serum (10\%), penicillin $(100 \mathrm{U} / \mathrm{ml})$ and streptomycin $(100 \mu \mathrm{g} / \mathrm{ml})$, and $0.04 \%$ of M-CSF. The dishes were incubated at $37^{\circ} \mathrm{C}$ in humidified atmosphere of $5 \% \mathrm{CO}_{2}$. After 4 days, BM-derived macrophages in primary culture were harvested and identified morphologically by the adhesion of bottom of dish. The supernatant medium was removed from the dishes and replaced with $5 \mathrm{ml}$ fresh medium (RPMI with L-glutamine added 10\% fetal bovine serum), and adherent macrophages peeled with a rubber brush. Then, the cells in the medium was collected and seeded at a concentration of $10^{5}$ cell/well in a 96-well plate. After overnight incubation, each well was washed with the above medium and infected with the desired concentrations of bacteria. After 2 hours of incubation, the wells were washed with the medium to remove un-attached bacteria [25], and then the cells were incubated in 5\% $\mathrm{CO}_{2}$ with or without hyperoxia. After macrophages were infected with L. pneumophila, shrunken cells (apoptotic cells) but not necrosis cells were observed by microscopic analysis (data not shown).

\section{Determination of caspases activity}

To evaluate induction of apoptosis, caspase- 3 and -8 activities were determined in the homogenates of the lungs of wild-type and Fas-deficient mice with pneumonia. To confirm the activities of caspase cascade in apoptosis, Caspase- 3 and -8 activities were determined by a colorimetric assay (R\&D Systems, Minneapolis, $\mathrm{MN})$. The data were expressed as a fold increase, comparing to those of control mice $(n=5)$.

\section{Murine cytokines ELISA}

Murine cytokines (TNF- $\alpha$, IL-6, IL-12) were quantitated using specific ELISAs (R\&D systems, Minneapolis, MN) according to manufacturerers' instructions.

\section{Cell viability by Tetracolor ${ }^{\circledR}$}

Incubated bone marrow-derived macrophages (after Trypsin-EDTA treatment) were added in 96-well plates $\left(1 \times 10^{5} /\right.$ well $)$, and incubated for $24-48 \mathrm{hr}$ at $37^{\circ} \mathrm{C} .10$ $\mu \mathrm{l}$ of Tetracolor $\mathrm{ONE}^{\circledR}$ were added in each well and incubated for $24 \mathrm{hr}$ at $37^{\circ} \mathrm{C}$. Measurement was determined by ELISA.

\section{Statistical analysis}

Statistical significance was determined using the unpaired, two-tailed alternate Welch $t$ test. Calculations were performed using JSTAT for Windows (Masato Sato, Japan). Statistic analyses of survival curves were performed by using Delta Graph (SPSS Inc.).

\section{Results}

Bacterial number in the lungs of mice with Legionella pneumonia

It has been reported that Fas-deficient mice may be more resistant to Legionella pneumonia infection in the setting of hyperoxia [22]. To explore the mechanisms of lower lethality of Fas-deficient mice with Legionella pneumonia in hyperoxia, we examined bacterial numbers in the lungs of wild-type and Fas-deficient mice. The results demonstrated clearly no differences of the bacterial numbers in the lungs between wild-type and Fas-deficient mice, in both settings of normoxia and hyperoxia (Figure 1). In in-vitro experiments using BMderived macrophages, we observed no differences of bacterial numbers in macrophages derived from wildtype and Fas-deficient mice, in despite of the condition normoxia and hyperoxia (data not shown). These results suggested that bacterial number may not be a critical factor responsible for a mechanism of higher resistance of Fas-deficient mice against Legionella pneumonia in the setting of hyperoxia.

\section{Effects of hyperoxia on Legionella-induced apoptosis in the lungs of mice}

In a previous study, we found that significantly lower values of histone-associated DNA fragments were observed in the lungs of Fas-deficient mice in hyperoxia compared to in normoxic condition [22]. Therefore, we examined the roles of apoptosis of Legionella pneumonia in wild-type and Fas-deficient mice. We explored

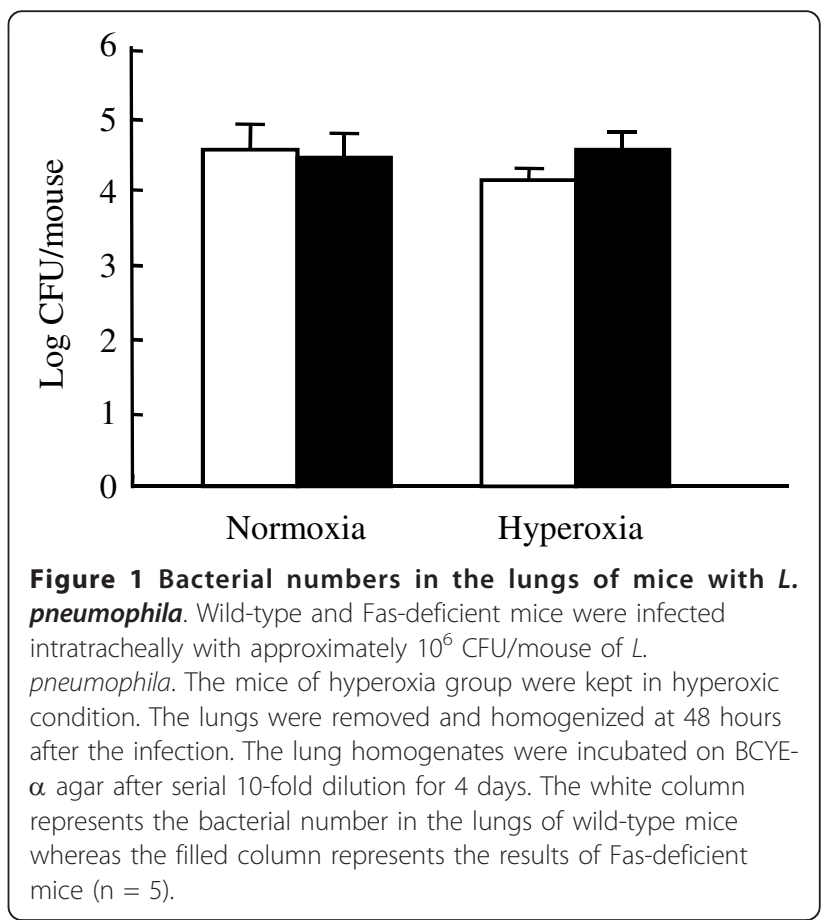


the activities of caspase-3 (an end-stage marker for apoptosis) and caspase-8 (a marker of apoptosis associated with the Fas-signaling system) in the lungs of mice. For both markers, there were no differences in the lungs between wild-type and Fas-deficient mice when they were kept in normoxic condition (Figure 2). On the other hand, significantly lower values of caspase- 3 and caspase- 8 were observed in Fas-deficient mice under hyperoxic condition. These results suggested less induction of apoptosis in the lungs of Fas-deficient mice kept in hyperoxia, as evidenced by several factors, such as histone-associated DNA fragments and caspase-3, caspase-8.

Inflammatory cytokines in the lungs of wild-type and Fasdeficient mice

We examined inflammatory cytokines, such as TNF-a, IL-6 and IL-12, in the lungs of wild-type and Fas-deficient mice kept in normoxic or hyperoxic condition (Figure 3). In control mice, there was a trend of lower values of these factors in the setting of hyperoxia. When the values were compared in wild-type and Fas-deficient mice, statistically significant differences were not demonstrated between wild-type and Fas-deficient mice in both normoxic and hyperoxic conditions.

\section{Viability of BM-derived macrophages infected with $L$. pneumophila}

Finally, viability of BM-derived macrophages from wildtype and Fas-deficient mice was compared after the infection with L. pneumophila (Figure 4). In normoxic condition, there were no differences of viability of macrophages between wild-type and Fas-deficient mice. On the other hand, significantly higher viability was demonstrated in BM-derived macrophages from Fas- deficient mice, when the infected cells were kept in hyperoxia. Shrunken cells were frequently observed in wild type mice in hyperoxia by microscopic analysis (data not shown). These data suggested that BM-derived macrophages from Fas-deficient mice may be more resistant to L. pneumophila-induced cytotoxicity in the setting of hyperoxia.

\section{Discussion}

Apoptosis can be triggered through two major pathways, one implicating death receptor ligation (e.g. Fas and TNF- $\alpha$ ) and the other is the release of cytochrome c from mitochondria [15]. In the lungs and pulmonary cells, several investigators have reported that the Fasmediated signaling system may be an important developmental regulator for induction of apoptosis [26,27]. These "death-inducing" receptors recruit the deathinducing signaling complex through interaction with adaptor proteins, such as Fas associated death domain protein (FADD). In turn, FADD recruits caspase-8. Although a variety of known and unknown anti-apoptotic and pro-apoptotic factors may play a role, subsequent activation of proteases through mitochondriadependent or -independent pathways results in activation of the key effector enzyme, caspase-3. Activation of executioner caspases results in DNA laddering, characteristic of apoptotic cells, and to the cleavage of cytoskeletal proteins. We observed less exaggerated changes of the initiator caspase- 8 and effector caspase -3 and DNA fragmentation (histone-associated DNA fragments) in the lungs of Fas-deficient mice under hyperoxia. However, how hyperoxia and Legionella infection are interacting and exaggerating each other in the lungs of mice, particularly the molecular role of Fas remains unknown. The future use of animal models deficient in another
Caspase-3

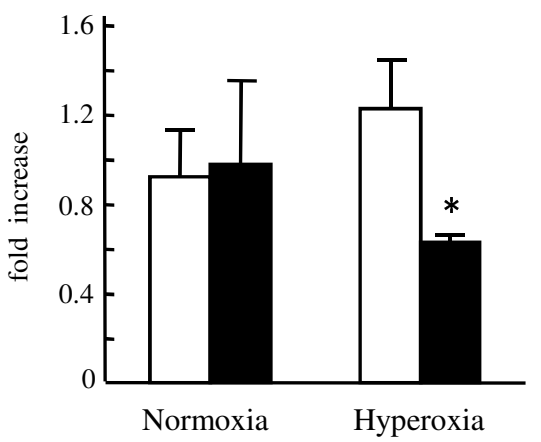

Caspase-8

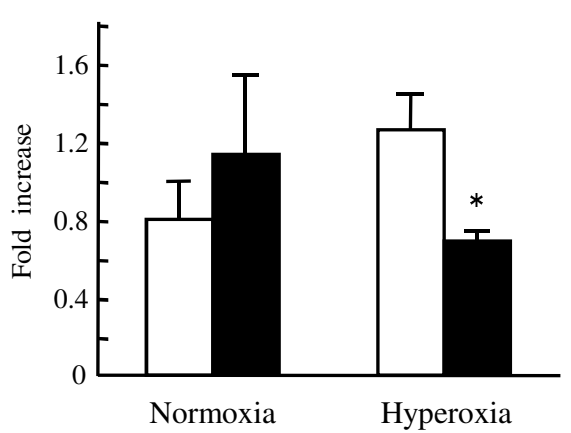

Figure 2 Caspase-3 and caspase-8 in the lungs of mice with L. pneumophila. Wild-type and Fas-deficient mice were infected intratracheally with approximately $10^{6} \mathrm{CFU} /$ mouse of L. pneumophila. One group was kept in room air condition and another group was placed in a hyperoxic condition. Lungs were removed and homogenized at 48 hours after the infection. Caspase activity was quantified by the ELISA, as described in materials and methods. The white column represents the results of the lungs of wild-type mice whereas the filled column represents the results of Fas-deficient mice $(n=5) .{ }^{*}<<0.01$, compared to those of wild-type mice. 


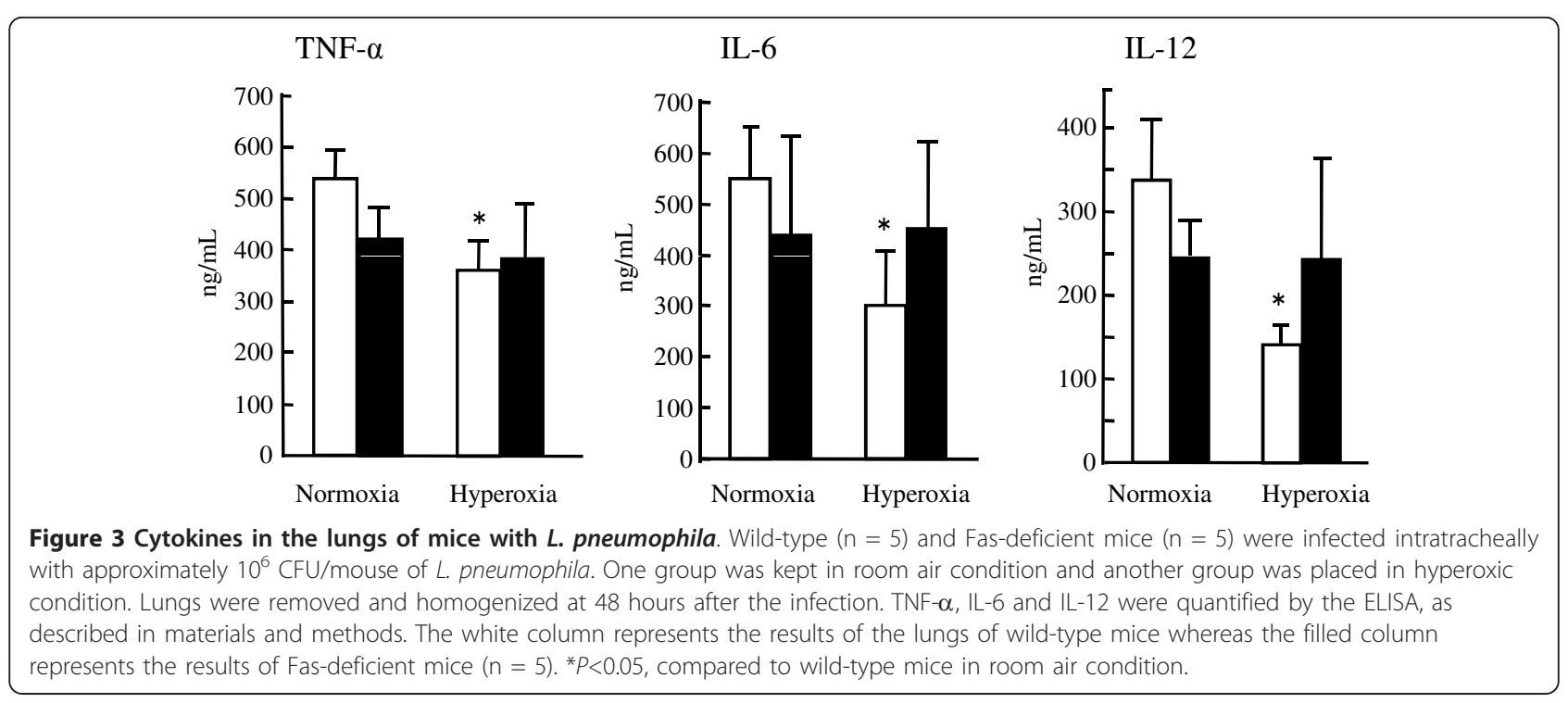

protein of the apoptotic pathway may lead to a clearer understanding of this.

Apoptosis has been described as a major death mechanism in hyperoxia-induced lung injury in various animal models in vivo [18,28-31]. Barazzone and collaborators have reported increased pulmonary Fas mRNA levels in adult mice exposed to $100 \%$ oxygen, although they failed to demonstrate survival advantage in Fasdeficient $l p r$ mice exposed to hyperoxia [21]. In concordance with this finding, De Paepe and associates have demonstrated that Fas gene silencing by siRNAs significantly reduced hyperoxia-induced apoptosis [32]. In contrast, several investigators have reported that other

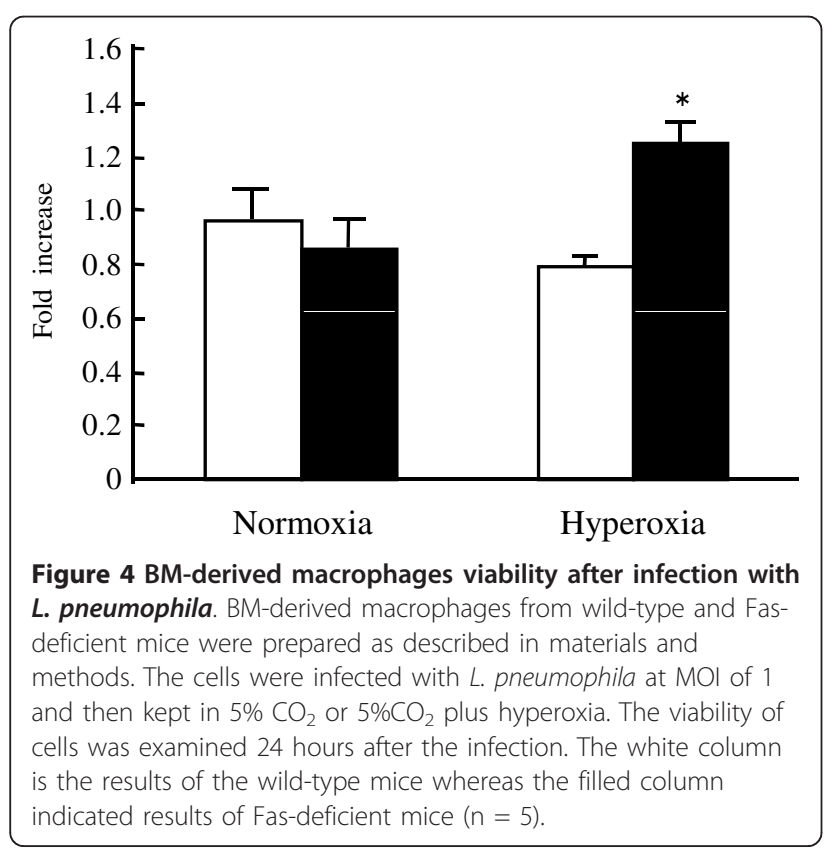

apoptotic signaling pathways, such as mitochondrial pathways and pro-apoptotic factor Bax, may participate in the regulation of hyperoxia-induced cell death [33-35]. Taken together, these data suggest that Fasmediated signaling and apoptosis, in addition to other intrinsic apoptosis-regulating mechanisms, may be involved in the pathogenesis of hyperoxia-induced lung injuries.

L. pneumophila has been shown to induce apoptosis within macrophages, monocytic cells and alveolar epithelial cells $[10,12]$. Although the mechanisms of L. pneumophila-associated apoptosis are not well understood, there are at least two possibilities. The first is that L. pneumophila may induce apoptosis through ligation of death receptors, such as Fas and TNF-receptor, by bacterial surface components or by secreted bacterial factors. Another possibility is that translocation of apoptotic factor(s), probably through the Dot/Icm secretion machinery of bacteria, followed by direct activation of caspases within the cytosol. Previously, Gao and AbuKwaik demonstrated that activation of caspase-3, but not caspase-1, is essential for apoptosis induced upon infection by L. pneumophila [11], but the initial events of caspase induction remained unclear at that time. Molmeret and associates have shown that caspase-3 activation by L. pneumophila is independent of all the known apoptotic pathways, such as the extrinsic and intrinsic, that converge on the activation of caspase-3 [36]. Neumeister and collaborators have shown that L. pneumophila induced comparable apoptosis in Faspositive and Fas-negative human monocytic cells, in which correlated caspase activation and mitochondrial cytochrome $c$ release were demonstrated [37]. It seems likely that apoptosis induced by L. pneumophila is independent of the interaction between bacteria or bacterial 
products with the death receptor Fas. Furthermore, Fischer and associates have reported that caspase-8-deficient Jurkat cells still underwent cell death, suggesting that caspase- 8 is not the relevant initiator caspase in L. pneumophila-induced apoptosis [38]. These data suggested that it may be important to consider the possibility of activation of apoptosis-related enzymes in a retrograde fashion in L. pneumophila-induced apoptosis.

Several cytokines, chemokines and growth factors have been reported to play a critical role in the pathogenesis of hyperoxia-related lung injury. These include IL-6, IL8, IL-11, granulocyte-macrophage colony-stimulating factor (GM-CSF) and keratinocyte growth factor (KGF). In the present study, only limited cytokines were examined in L. pneumophila-infected lungs of wild-type and Fas-deficient mice under hyperoxia. The data of TNF-a, IL-6 and IL-12 demonstrated no characteristic changes associated with lethality of mice and alterations in apoptosis markers. Further studies examining other factors, such as IL-11, GM-CSF and KGF, may be important to correctly characterize the roles and significance of cytokines and growth factors in Legionella pneumonia under hyperoxia.

The present data demonstrate that BM-macrophages from Fas-deficient mice were more resistant to L. pneumophila infection than those from wild-type mice in the setting of hyperoxia. These data are consistent with the survival data and the apoptosis markers in Fas-deficient mice with L. pneumophila pneumonia. The Dot/Icm secretion system of L. pneumophila may be a crucial factor determining cytotoxic effects of this organism, because bacterial mutants deficient in this system demonstrated a striking reduction of the capacity to cause cytotoxicity through induction of apoptosis [36,39]. Although the mechanisms of this phenomenon remain incompletely known, BM-derived $\mathrm{M} \phi$ experiments may provide an opportunity to examine an interaction between Dot/Icm secretion system of L. pneumophila and hyperoxia-mediated alterations in host cellular defense systems.

The present data suggest that the blocking of apoptosis, especially the Fas-mediated cascade, may be a potential candidate for a new therapeutic approach against $L$. pneumophila pneumonia under hyperoxia. Although it may be critical to understand the molecular and cellular pathogenesis of the events occurred in the lungs of these individuals, silencing of Fas by siRNA and blocking of Dot/Icm secretion system of L. pneumophila may be attractive strategies. IAP (Inhibitor of apoptosis) family proteins such as survivin may be potential candidates for therapy [40]. In addition, antioxidants such as glutathione may be also a potential therapeutic candidate $[23,41]$. Since L. pneumophila pneumonia is still a potentially lethal infectious diseases and significant numbers of the cases are treated with supplementation of high concentrations of oxygen, further investigations are warranted for better understanding of the mechanisms of the diseases and to search for life-saving therapeutic strategies.

\section{Acknowledgements}

We would like to express our deep appreciation to Tse Hsien Koh for his critical comments and careful reviewing of the manuscript. This study was supported by Grant-in-Aid for Scientific Research B (16390289) and grant of the strategic basis on research grounds for non-governmental schools at Heisei 20th from Ministry of Education, Culture, Sports, Science and Technology-Japan (\$0801028).

\section{Author details}

'Department of Microbiology and Infectious Diseases, Toho University Faculty of Medicine, Tokyo 143-8540, Japan. ${ }^{2}$ Division of Respiratory Medicine and Infection Control and Prevention Niigata University Graduate School of Medical and Dental Sciences, Niigata University Medical School, Niigata 951-8510, Japan. ${ }^{3}$ Department of Microbiology, Tokyo Medical University, Tokyo, Japan.

\section{Authors' contributions}

TM was involved in the study concept, data collection, data analysis and prepared the first draft of manuscript. SK participated in conception of study design and revision of manuscript. TM, YT and FG contributed to the revision of the manuscript. YK managed the study and edited the manuscript. All authors have read and approve the final manuscript.

\section{Competing interests}

The authors declare that they have no competing interests.

Received: 17 August 2010 Accepted: 6 April 2011

Published: 6 April 2011

\section{References}

1. Marston BJ, Lipman HB, Breiman RF: Surveillance for Legionnaires' disease. Risk factors for morbidity and mortality. Arch Intern Med 1994, 154(21) 2417-2422.

2. Reingold AL: Role of Legionellae in acute infections of the lower respiratory tract. Rev Infect Dis 1988, 10(5): 1018-1028.

3. Tkatch LS, Kusne S, Irish WD, Krystofiak S, Wing E: Epidemiology of Legionella pneumonia and factors associated with legionella-related mortality at a tertiary care center. Clin Infect Dis 1998, 27(6): 1479-1486.

4. Torres A, Serra-Batlles J, Ferrer A, Jimenez P, Celis R, Cobo E, RodriguezRoisin R: Severe community-acquired pneumonia. Epidemiology and prognostic factors. Am Rev Respir Dis 1991, 144(2): 312-318.

5. el-Ebiary M, Sarmiento X, Torres A, Nogue S, Mesalles E, Bodi M, Almirall J: Prognostic factors of severe Legionella pneumonia requiring admission to ICU. American journal of respiratory and critical care medicine 1997, 156(5): 1467-1472

6. Pedro-Botet ML, Sabria-Leal M, Sopena N, Manterola JM, Morera J, Blavia R, Padilla E, Matas L, Gimeno JM: Role of immunosuppression in the evolution of Legionnaires' disease. Clin Infect Dis 1998, 26(1): 14-19.

7. Horwitz MA, Silverstein SC: Legionnaires' disease bacterium (Legionella pneumophila) multiples intracellularly in human monocytes. The Journal of clinical investigation 1980, 66(3): 441-450.

8. Nash TW, Libby DM, Horwitz MA: Interaction between the legionnaires' disease bacterium (Legionella pneumophila) and human alveolar macrophages. Influence of antibody, lymphokines, and hydrocortisone. The Journal of clinical investigation 1984, 74(3): 771-782.

9. Mody $\mathrm{CH}$, Paine R, Shahrabadi MS, Simon RH, Pearlman E, Eisenstein Bl, Toews GB: Legionella pneumophila replicates within rat alveolar epithelial cells. J Infect Dis 1993, 167(5): 1138-1145.

10. Muller A, Hacker J, Brand BC: Evidence for apoptosis of human macrophage-like $\mathrm{HL}-60$ cells by Legionella pneumophila infection. Infection and immunity 1996, 64(12): 4900-4906.

11. Gao LY, Abu Kwaik Y: Activation of caspase 3 during Legionella pneumophila-induced apoptosis. Infection and immunity 1999, 67(9): 4886-4894. 
12. Gao LY, Abu Kwaik Y: Apoptosis in macrophages and alveolar epithelial cells during early stages of infection by Legionella pneumophila and its role in cytopathogenicity. Infection and immunity 1999, 67(2): 862-870.

13. Nagata S: Apoptosis by death factor. Cell 1997, 88(3): 355-365.

14. Rathmell JC, Thompson CB: The central effectors of cell death in the immune system. Annu Rev Immunol 1999, 17: 781-828.

15. Burz C, Berindan-Neagoe I, Balacescu O, Irimie A: Apoptosis in cancer: key molecular signaling pathways and therapy targets. Acta oncologica (Stockholm, Sweden) 2009, 48(6): 811-821.

16. Weinrauch $Y$, Zychlinsky A: The induction of apoptosis by bacterial pathogens. Annu Rev Microbiol 1999, 53: 155-187.

17. Jesenberger V, Procyk KJ, Yuan J, Reipert S, Baccarini M: Salmonellainduced caspase-2 activation in macrophages: a novel mechanism in pathogen-mediated apoptosis. J Exp Med 2000, 192(7): 1035-1046.

18. Waxman AB, Einarsson $O$, Seres $T$, Knickelbein RG, Warshaw JB, Johnston R, Homer RJ, Elias JA: Targeted lung expression of interleukin-11 enhances murine tolerance of $100 \%$ oxygen and diminishes hyperoxia-induced DNA fragmentation. The Journal of clinical investigation 1998, 101(9): 1970-1982.

19. Baleeiro CE, Wilcoxen SE, Morris SB, Standiford TJ, Paine R: Sublethal hyperoxia impairs pulmonary innate immunity. J Immunol 2003, 171(2): 955-963.

20. Barazzone C, White CW: Mechanisms of cell injury and death in hyperoxia: role of cytokines and $\mathrm{Bcl}-2$ family proteins. American journal of respiratory cell and molecular biology 2000, 22(5): 517-519.

21. Barazzone C, Horowitz S, Donati YR, Rodriguez I, Piguet PF: Oxygen toxicity in mouse lung: pathways to cell death. American journal of respiratory cell and molecular biology 1998, 19(4): 573-581.

22. Tateda K, Deng JC, Moore TA, Newstead MW, Paine R, Kobayashi N, Yamaguchi K, Standiford TJ: Hyperoxia mediates acute lung injury and increased lethality in murine Legionella pneumonia: the role of apoptosis. J Immunol 2003, 170(8): 4209-4216.

23. Nara C, Tateda K, Matsumoto T, Ohara A, Miyazaki S, Standiford TJ, Yamaguchi K: Legionella-induced acute lung injury in the setting of hyperoxia: protective role of tumour necrosis factor-alpha. Journal of medical microbiology 2004, 53(Pt 8): 727-733.

24. Gregory SH: Substratum-dependent proliferation and survival of bone marrow-derived mononuclear phagocytes. J Leukoc Biol 1988, 43(1): 67-79.

25. Swanson MS, Isberg RR: Association of Legionella pneumophila with the macrophage endoplasmic reticulum. Infection and immunity 1995, 63(9): 3609-3620.

26. Matsuda N, Yamamoto S, Takano K, Kageyama S, Kurobe Y, Yoshihara Y, Takano Y, Hattori Y: Silencing of fas-associated death domain protects mice from septic lung inflammation and apoptosis. American journal of respiratory and critical care medicine 2009, 179(9): 806-815.

27. Galani V, Tatsaki E, Bai M, Kitsoulis P, Lekka M, Nakos G, Kanavaros P: The role of apoptosis in the pathophysiology of Acute Respiratory Distress Syndrome (ARDS): An up-to-date cell-specific review. Pathology, research and practice.

28. Mantell LL, Horowitz S, Davis JM, Kazzaz JA: Hyperoxia-induced cell death in the lung-the correlation of apoptosis, necrosis, and inflammation. Annals of the New York Academy of Sciences 1999, 887: 171-180.

29. Mantell LL, Shaffer TH, Horowitz S, Foust R, Wolfson MR, Cox C, Khullar P, Zakeri Z, Lin L, Kazzaz JA, et al: Distinct patterns of apoptosis in the lung during liquid ventilation compared with gas ventilation. American journal of physiology 2002, 283(1): L31-41.

30. McGrath-Morrow SA, Stahl J: Apoptosis in neonatal murine lung exposed to hyperoxia. American journal of respiratory cell and molecular biology 2001, 25(2): 150-155

31. Otterbein LE, Chin BY, Mantell LL, Stansberry L, Horowitz S, Choi AM: Pulmonary apoptosis in aged and oxygen-tolerant rats exposed to hyperoxia. The American journal of physiology 1998, 275(1 Pt 1): L14-20.

32. De Paepe ME, Mao Q, Chao Y, Powell JL, Rubin LP, Sharma S: Hyperoxiainduced apoptosis and Fas/FasL expression in lung epithelial cells. American journal of physiology 2005, 289(4): L647-659.

33. Perkowski S, Sun J, Singhal S, Santiago J, Leikauf GD, Albelda SM: Gene expression profiling of the early pulmonary response to hyperoxia in mice. American journal of respiratory cell and molecular biology 2003, 28(6): 682-696.
34. Ward NS, Waxman AB, Homer RJ, Mantell LL, Einarsson O, Du Y, Elias JA: Interleukin-6-induced protection in hyperoxic acute lung injury. American journal of respiratory cell and molecular biology 2000, 22(5): 535-542.

35. Wang X, Ryter SW, Dai C, Tang ZL, Watkins SC, Yin XM, Song R, Choi AM: Necrotic cell death in response to oxidant stress involves the activation of the apoptogenic caspase-8/bid pathway. The Journal of biological chemistry 2003, 278(31): 29184-29191.

36. Molmeret M, Zink SD, Han L, Abu-Zant A, Asari R, Bitar DM, Abu Kwaik Y: Activation of caspase- 3 by the Dot/lcm virulence system is essential for arrested biogenesis of the Legionella-containing phagosome. Cell Microbiol 2004, 6(1): 33-48.

37. Neumeister B, Faigle M, Lauber K, Northoff H, Wesselborg S: Legionella pneumophila induces apoptosis via the mitochondrial death pathway. Microbiology 2002, 148(Pt 11): 3639-3650.

38. Fischer SF, Vier J, Muller-Thomas C, Hacker G: Induction of apoptosis by Legionella pneumophila in mammalian cells requires the mitochondrial pathway for caspase activation. Microbes and infection/Institut Pasteur 2006, 8(3): 662-669.

39. Zink SD, Pedersen L, Cianciotto NP, Abu-Kwaik Y: The Dot/lcm type IV secretion system of Legionella pneumophila is essential for the induction of apoptosis in human macrophages. Infection and immunity 2002, 70(3): 1657-1663.

40. Altieri DC: Survivin and IAP proteins in cell-death mechanisms. The Biochemical journal 2010, 430(2): 199-205.

41. Nagata K, Iwasaki Y, Yamada T, Yuba T, Kono K, Hosogi S, Ohsugi S, Kuwahara $H$, Marunaka $Y$ : Overexpression of manganese superoxide dismutase by $\mathrm{N}$-acetylcysteine in hyperoxic lung injury. Respiratory medicine 2007, 101(4): 800-807.

doi:10.1186/1756-0500-4-107

Cite this article as: Maeda et al:: Hyperoxia accelerates Fas-mediated signaling and apoptosis in the lungs of Legionella pneumophila pneumonia. BMC Research Notes 2011 4:107.

\section{Submit your next manuscript to BioMed Central and take full advantage of:}

- Convenient online submission

- Thorough peer review

- No space constraints or color figure charges

- Immediate publication on acceptance

- Inclusion in PubMed, CAS, Scopus and Google Scholar

- Research which is freely available for redistribution

Submit your manuscript at www.biomedcentral.com/submit
Biomed Central 